\title{
His bundle tachycardia
}

INSERM

\section{Source}

INSERM. (1999). Orphanet: an online rare disease and orphan drug data base. His bundle tachycardia. ORPHA:3283

$\mathrm{H}$ is bundle tachycardia is a very rare congenital genetic tachyarrhythmia characterized by incessant tachycardia and high morbidity and mortality. 